\title{
O uso de substâncias psicoativas entre adolescentes e a estratégia de redução de danos: revisão integrativa da literatura
}

\author{
Letícia Ribeiro Bombardelli", Silvana Ceolin, Vera Beatriz Pinto Zimmermann Weber \\ Sociedade Educacional Três de Maio (SETREM) - Três de Maio, RS, Brasil
}

Histórico do Artigo
Recebido em:
09/09/2020
Aceito em:
22/05/2020
Palavras-chave:
Redução de danos;
adolescente;
enfermagem.

Keywords:

Harm reduction; adolescent; nursing

\begin{abstract}
RESUMO
O uso de substâncias psicoativas entre os adolescentes cresce progressivamente no Brasil e no mundo. Este estudo objetivou conhecer as estratégias de redução de danos e seus possíveis obstáculos, apresentados na literatura nacional. Trata-se de uma revisão integrativa, utilizando artigos científicos. A coleta de dados foi realizada em março de 2019, nas bases eletrônicas Google Acadêmico e LILACS (Literatura Latino-Americana e do Caribe em Ciências da Saúde), utilizado o sinônimo "redução de danos" e o descritor "adolescente", com o operador boleano "and". Foram analisados 13 artigos e organizados em três categorias: "A fase da adolescência e o uso de substâncias psicoativas", "Redução de danos" e "Papel do enfermeiro". Evidenciou-se a importância da abordagem do adolescente quanto a temática na escola, incluindo educadores, pais, profissionais de saúde e a comunidade em geral. São necessários programas e práticas humanizadas, adequados ao contexto em que se inserem, que considerem as singularidades dos seus usuários e não enfatizem somente a substância.
\end{abstract}

The use of psychoactive substances among adolescents and the harm reduction strategy: an integrative review of the literature

\section{ABSTRACT}

The use of psychoactive substances among adolescents grows progressively in Brazil and worldwide. This study aimed to know the harm reduction strategies and their possible obstacles, presented in the national literature. It is an integrative review, using scientific articles. Data collection was carried out in March 2019, on the electronic databases Google Scholar and LILACS (Latin American and Caribbean Literature in Health Sciences), using the synonym "harm reduction" and the descriptor "adolescent", with the operator Boolean "and". 13 articles were analyzed and organized into three categories: "The adolescence phase and the use of psychoactive substances", "Harm reduction" and "Role of the nurse". The importance of the adolescent's approach regarding the theme at school was evidenced, including educators, parents, health professionals and the community in general. Humanized programs and practices are necessary, appropriate to the context in which they operate, which consider the singularities of their users and do not emphasize only the substance.

\section{Introdução}

A estratégia de redução de danos se refere às políticas, programas e práticas que visam primeiramente minimizar riscos e danos de natureza biológica, psicossocial e econômica provocados ou secundários ao uso de substâncias psicoativas (1). Na área da educação, o campo da redução de danos considera que os principais danos associados ao uso das substâncias psicoativas na adolescência não dizem respeito aos aspectos farmacológicos da droga em si, mas ao conjunto que cerca o adolescente e o uso. A própria overdose, está mais relacionada com a falta de informação e a inexperiência em lidar com a droga do que com alguma inevitabilidade perigosa de uma droga em particular (2).

O Ministério da Saúde propõe que indivíduo seja considerado de maneira integral,

\footnotetext{
*Autor correspondente: leticiarbombardelli@gmail.com (Bombardelli, LR.)
} 
entendendo o consumo de substâncias psicoativas como um problema de saúde pública, e também social. Desse modo, é importante trabalhar com as singularidades, na intenção de delinear estratégias de vida dos usuários, aumentando o grau de liberdade e de corresponsabilidade; fazê-lo protagonista de suas ações (3).

A elaboração do problema de pesquisa ocorreu a partir de uma questão norteadora: quais são os obstáculos e estratégias de redução de danos no uso de substâncias psicoativas entre adolescentes apresentados na literatura nacional?

Frente a problemática posta, este estudo se alicerça dentre as teorias de enfermagem que fundamentam a assistência de enfermagem, e como base terá a Teoria do Autocuidado de Dorothea Orem de 1971 e 1980 que apresenta grande importância no contexto do indivíduo que faz uso das substâncias psicoativas (4).

Para Orem, aquele que promove o autocuidado, para si mesmo ou para outra pessoa, é agente de autocuidado, que sempre sofre influências sobre o desenvolvimento, cultura e de base experimental. Assim, o enfermeiro pode ser um agente de autocuidado terapêutico, quando um cliente não pode suprir-se, por si mesmo, dos cuidados que necessita (4).

Ainda, segundo a teorista, a intervenção de cuidado se faz através de cinco modos: agir ou fazer para o outro, guiar o outro, apoiar o outro, ensinar o outro e proporcionar ambiente. Dessa forma, é possível alcançar as formas do cuidar, favorecendo a elaboração da assistência de enfermagem individualizada com base nas teorias de enfermagem.

É importante acreditar no potencial de recuperação, integração social de cada indivíduo a partir de sua autonomia: auto cuidado e autogerenciamento, assim como, o cuidado proporcionado ao mesmo. Dessa maneira, o processo de enfermagem facilita o cuidado prestado ao indivíduo e sua família, aplicada com base nas teorias de enfermagem para que resulte em uma melhor assistência.

O presente estudo tem por objetivo, conhecer os obstáculos e estratégias de redução de danos no uso de substâncias psicoativas entre adolescentes apresentados na literatura nacional. Assim, foi realizada uma revisão integrativa de literatura entre artigos disponibilizados na íntegra que abordaram a temática proposta.

\section{Materiais e métodos}

A revisão integrativa da literatura é um método de pesquisa que permite busca, avaliação crítica e síntese das evidências existentes do tema investigado, sendo o seu resultado o estado atual do conhecimento do tema pesquisado, a implementação de intervenções efetivas na assistência à saúde, bem como a identificação de lacunas que direcionam para o desenvolvimento de futuras pesquisas (5).

Para desenvolver a revisão integrativa realizou-se uma divisão que se dá através de seis etapas: 1) escolha e definição do tema, e a elaboração da questão de pesquisa; 2) coleta de dados, estabelecimento de critérios para inclusão e exclusão de estudos/amostragem ou busca na literatura; 3) definição das informações; 4) avaliação dos estudos; 5) análises dos resultados; 6) apresentação da revisão integrativa (5).

$\mathrm{Na}$ primeira etapa, foi formulada a questão de pesquisa: quais são os obstáculos e estratégias de redução de danos no uso de substâncias psicoativas entre adolescentes apresentados na literatura nacional?

$\mathrm{Na}$ segunda etapa realizou-se a coleta de dados por meio do levantamento bibliográfico através das bases eletrônicas Google Acadêmico e LILACS (Literatura Latino-Americana e do Caribe em Ciências da Saúde) utilizando os descritores do DECS (Descritores em Ciências da Saúde). Foram realizados vários cruzamentos entre os descritores "drogas", "adolescentes", "educação" e "prevenção", contudo, os artigos derivados destes 
cruzamentos não abordavam a temática redução de danos. Por isso, foi utilizado o sinônimo "redução de danos" e o descritor "adolescente", com o operador boleano "and". A busca foi realizada no mês de março de 2019. Os critérios de inclusão para esta revisão foram: artigos em português sem delimitação do ano de publicação, com textos completos disponíveis e de acesso livre; e os critérios de exclusão: artigos que não relacionavam-se à temática estudada, teses e dissertações, artigos em língua estrangeira pois não incluíam o foco de interesse da pesquisa, e artigos que não se encontrava disponível o texto completo. Segue a Figura 1 para melhor entendimento.

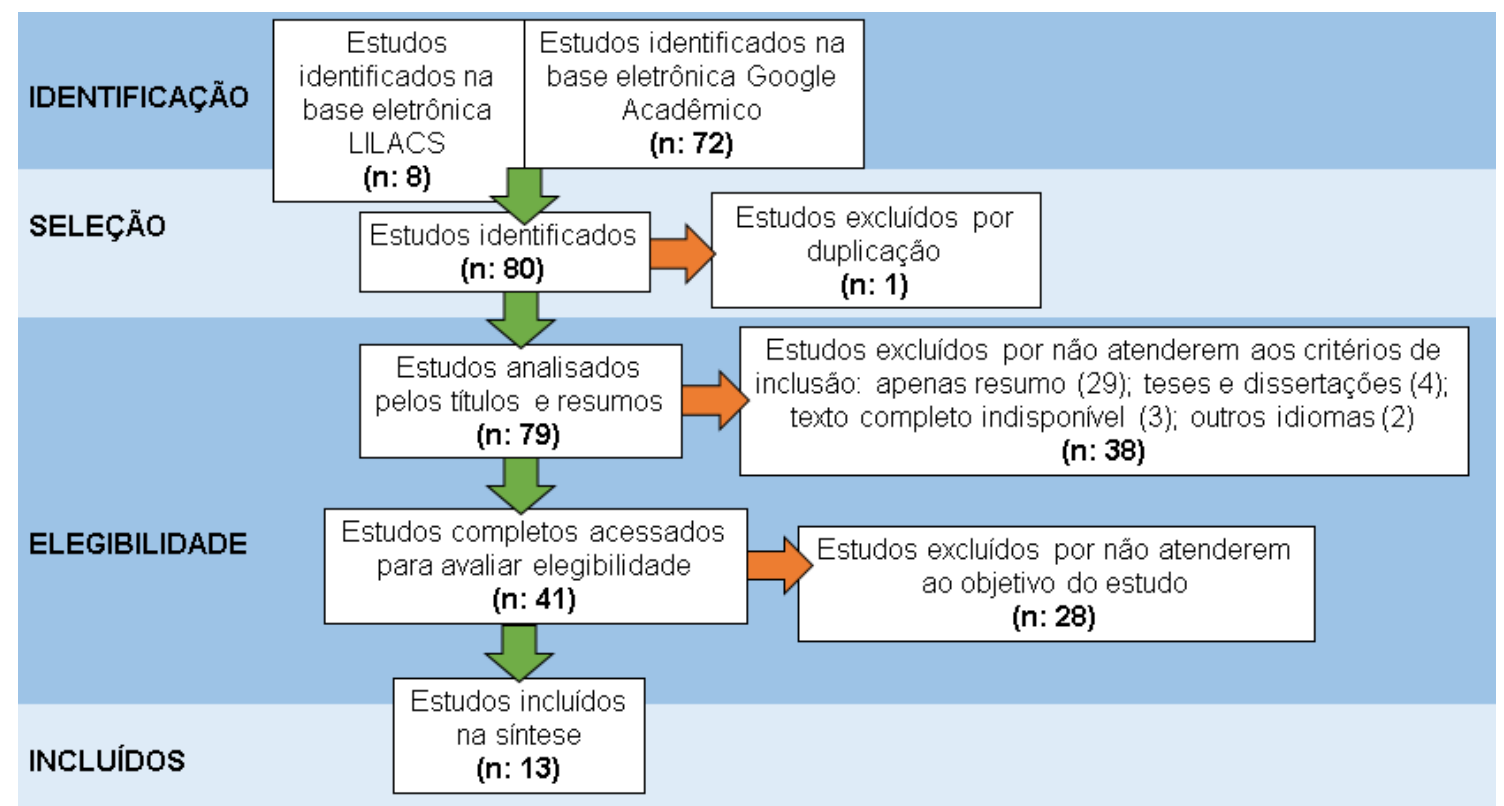

Figura 1 - Fluxograma da seleção das publicações para a revisão integrativa, baseado no modelo PRISMA.

Na terceira etapa, definição das informações, foi elaborado um quadro comparativo, que serviu de instrumento para contemplar as seguintes variáveis: identificação do artigo, título, metodologia e resultados.

Na quarta etapa, a técnica de análise dos dados utilizada foi a análise temática de Minayo (6), a qual consiste em pré-análise, exploração do material e tratamento dos resultados obtidos e interpretação. A partir disso, foram elaboradas três categorias temáticas: I) A fase da adolescência e o uso de substâncias psicoativas; II) Redução de danos e III) Papel do enfermeiro.

$\mathrm{Na}$ quinta etapa, realizou-se a discussão dos resultados com outros estudos sobre a temática em evidência, seguida da sexta etapa, que consistiu na apresentação das evidências encontradas. Foi realizado um quadro (Quadro 1) para melhor visualização.

\section{Resultados e discussão}

A caracterização dos estudos sucedeu-se da seguinte forma: três artigos com metodologia de pesquisa qualitativa dos anos de 2007, 2009 e 2016; dois artigos de pesquisa descritiva dos anos de 2004 e 2015; seis artigos de revisão integrativa, quatro do ano de 2006, um de 2008 e um de 2013; um artigo de pesquisa descritiva quantiqualitativa do ano de 2013 e um artigo com metodologia de reflexão teórica do ano de 2008 . 
Quadro 1 - Descrição dos estudos incluídos na revisão integrativa, por identificação do artigo e resultados. Três de Maio (RS), 2019.

\begin{tabular}{|c|c|}
\hline $\begin{array}{l}\text { Identificação do } \\
\text { artigo }\end{array}$ & Resultados \\
\hline $\begin{array}{l}\text { A } 13 \\
(2016)\end{array}$ & $\begin{array}{l}\text { Educar para prevenir (escola); } \\
\text { Autonomia e capacidade de escolha do adolescente; } \\
\text { Redução de danos e senso crítico. }\end{array}$ \\
\hline $\begin{array}{c}\text { B } 7 \\
(2015)\end{array}$ & $\begin{array}{l}\text { Adolescência x classe social; } \\
\text { Abstinência como foco de tratamento. }\end{array}$ \\
\hline $\begin{array}{c}\text { C 8 } \\
(2013) \\
\end{array}$ & $\begin{array}{l}\text { Violência estrutural; } \\
\text { Redução de danos. } \\
\end{array}$ \\
\hline $\begin{array}{l}\text { D } 19 \\
(2013)\end{array}$ & $\begin{array}{l}\text { Políticas proibicionistas; } \\
\text { Redução de danos: pouco conhecida e cheia de polêmica. }\end{array}$ \\
\hline $\begin{array}{l}\text { E } 10 \\
(2013)\end{array}$ & $\begin{array}{l}\text { Percepção do adolescente em uso nocivo e abusivo do álcool sobre os riscos que } \\
\text { estão expostos; } \\
\text { Desejo de autonomia e liberdade. }\end{array}$ \\
\hline $\begin{array}{c}\text { F } 9 \\
(2013)\end{array}$ & $\begin{array}{l}\text { Abordagem ética da enfermagem na atenção a adolescentes usuários de drogas } \\
\text { lícitas e ilícitas; }\end{array}$ \\
\hline $\begin{array}{l}\text { G } 14 \\
(2013)\end{array}$ & $\begin{array}{l}\text { A escola: instituição social que faz mediação entre a pessoa e a sociedade; } \\
\text { Necessidade da construção de espaços de interação comunitária. }\end{array}$ \\
\hline $\begin{array}{l}\text { H } 16 \\
(2009)\end{array}$ & $\begin{array}{l}\text { O recurso às drogas deve ser entendido como ligado ao desenvolvimento psíquico } \\
\text { da adolescência; }\end{array}$ \\
\hline $\begin{array}{l}\text { I } 17 \\
(2008)\end{array}$ & $\begin{array}{l}\text { Adolescência: personalidade e fatores de risco; } \\
\text { Família e educação são primordiais na formação do jovem como sujeito. }\end{array}$ \\
\hline $\begin{array}{l}\text { J } 12 \\
(2008)\end{array}$ & $\begin{array}{l}\text { Adolescente usuário de substâncias psicoativas: tratamento contraditório; } \\
\text { relevância do papel da comunidade e da escola. }\end{array}$ \\
\hline $\begin{array}{l}\text { K } 28 \\
(2007)\end{array}$ & $\begin{array}{l}\text { Necessidade de adesão dos enfermeiros aos cuidados em relação ao usuário de } \\
\text { substâncias psicoativas: promoção da saúde. }\end{array}$ \\
\hline $\begin{array}{l}\text { L } 18 \\
(2006)\end{array}$ & $\begin{array}{l}\text { A redução de danos como estratégia de prevenção; } \\
\text { Escola promotora de saúde: ações de promoção de saúde. }\end{array}$ \\
\hline $\begin{array}{l}\text { M } 25 \\
(2004)\end{array}$ & $\begin{array}{c}\text { A abstinência não se constitui uma alternativa satisfatória para a maioria dos } \\
\text { usuários. }\end{array}$ \\
\hline
\end{tabular}

A partir da análise de conteúdo temática, os resultados foram organizados em três categorias temáticas: I) A fase da adolescência e o uso de substâncias psicoativas, da qual integram 10 artigos (A13, B7, C8, E10, F9, G14, H16, I17, J12 e L18), II) Redução de danos, com um rol de 6 artigos (A13, B7, C8, D19, L18 e M25) e III) O papel do enfermeiro, com 4 artigos fazendo parte da discussão (A11, E10, F9, I17 e K28).

\subsection{A fase da adolescência e o uso de substâncias psicoativas}

A adolescência é um período de descobertas, e muitas vezes acaba se tornando um período vulnerável já que os adolescentes estão com a personalidade em formação, curiosos a experimentar e acrescentar elementos novos em suas vivências. É nesse desejo por experimentar que os jovens muitas vezes vão ao encontro das substâncias psicoativas, sejam elas lícitas ou ilícitas. Entretanto, o artigo B (7) que investiga os efeitos da Redução de Danos (RD) sobre as escolhas e percepção de risco por adolescentes em situação de vulnerabilidade, afirma que a adolescência não é igual para jovens de diferentes classes e a condição de sofrimento pode ser compreendida de diferentes formas.

O estudo C (8) discute sobre a violência, intervenção precoce e redução de danos no que se refere ao problema do uso de álcool e outras substâncias psicoativas pelos jovens. A pesquisa identificou que o problema do uso de substâncias psicoativas e também da violência não atinge somente uma classe social específica, mas as condições de violência 
estrutural (ausência de proteção e garantia de direitos e necessidades) contribuem para o problema o segmento populacional com condições precárias, criando efeito em toda a sociedade. A violência estrutural limita as possibilidades de escolha da população menos favorecida, levando-a a decidir pela mendicância, tráfico de drogas e crime.

Compreender a violência estrutural como ausência de proteção e garantia de direitos e necessidades não só dos adolescentes, mas também da população desassistida indica a necessidade de uma estratégia voltada para a redução de danos, buscando atenuar os prejuízos ocasionados por esta violência. Pois, ao conceituar esses jovens como violadores de direitos, é importante pensar que em sua trajetória de vida, tiveram grande parte de seus direitos violados em um momento anterior. Nessas condições, o combate à violência estrutural depende do intermédio do Estado no avanço socioeconômico cultural do território (8).

Conforme o artigo F (9) que discorre acerca da abordagem ética da enfermagem na atenção a adolescentes que fazem uso das substâncias psicoativas, é nesta fase que encontra-se a maior quantidade de pessoas que fazem uso de substâncias psicoativas lícitas e ilícitas. A classe social pode determinar que substância essas pessoas consomem, levando em consideração uma variedade de preços que dependem, por exemplo, do nível de pureza e do tipo de substância desejada.

O estudo realizado no artigo E (10), de 2013, que buscou compreender a percepção de adolescentes em uso abusivo de álcool sobre os riscos que estão expostos e proteção para dependência da substância, mostra a identificação do uso nocivo e abusivo do álcool e investigou os riscos em que adolescentes estão expostos. O estudo identificou que a percepção dos adolescentes quanto aos riscos, baseiam-se na autonomia e liberdade, em ser adolescente, na relação familiar, na influência dos amigos e na inserção do álcool em suas vidas. E quanto a proteção, existe uma concepção sobre a supervisão familiar, acesso à bebida e a conscientização. Assim, torna-se possível o planejamento de ações eficazes na prevenção e controle do consumo que pode acarretar na dependência de álcool, enquanto adolescentes ou quando adultos.

Os jovens tendem a enfrentar o 'mal-estar na civilização' por meio de estratégias que envolvem, inclusive, o consumo das substâncias psicoativas. Confirmando tal compreensão, programas educacionais, como os realizados em outros países, mostram a necessidade de instruir os jovens em relação ao contato com as substâncias, pois já o 'amedrontamento' não condiz com a realidade e resolubilidade, o que fecha as portas para o diálogo aberto (11).

O artigo $\mathbf{J}$ (12), que tem como objetivo compreender as substâncias psicoativas e o adolescente em uma perspectiva sistêmica e relacional, apresenta que o adolescente que faz uso das substâncias muitas vezes recebe tratamentos contraditórios, sendo tratado como doente ou como criminoso, estigmatizando o jovem e contribuindo para mantê-lo na clandestinidade. Por isso, abordagens repressivas e de combate mostram-se insuficientes e ineficazes, tendo grande responsabilidade na reprodução da violência, refletindo nas estatísticas dos presídios superlotados e nas altas taxas de mortalidade de suas vítimas preferidas: os usuários negros e pobres. As medidas repressivas têm provocado mais prejuízos e perdas humanas do que o próprio efeito das substâncias psicoativas.

Com o objetivo de sensibilizar a comunidade escolar sobre os riscos e consequências do uso das substâncias psicoativas destacando a importância do conhecimento para a prevenção, o artigo A (13) menciona que um dos locais de maior socialização entre os jovens é a escola, sendo ela muitas vezes sujeita a venda e uso de substâncias psicoativas, que podem levar a consequências sociais, psicológicas e fisiológicas. O estudo também cita que o uso de substâncias psicoativas pode acometer alguns aspectos negativos, tais 
como: o aumento da incidência de doenças, criminalidade, violência, entre outros.

Conforme o artigo G (14), que aborda a prevenção do uso de substâncias psicoativas, relacionando adolescência, família e escola, um indivíduo não começa a fazer uso de alguma substância psicoativa por acaso ou por uma decisão isolada. O uso das substâncias psicoativas é fruto de diversos fatores, como o comportamento de assumir riscos e testar limites, traços da personalidade ou até transtornos psiquiátricos, necessidade de aceitação por amigos e pelo grupo, entre outros (15).

De acordo com o artigo H (16), que disserta sobre as concepções que norteiam as práticas de tratamento nas instituições que recebem adolescentes que fazem uso de substâncias psicoativas, o recurso à estas pode ser entendido como fundamentalmente ligado ao desenvolvimento psíquico que acontece na adolescência. Do mesmo modo, o artigo I (17) desenvolveu uma análise crítica sobre a necessidade de ações educativas na prevenção do uso das substâncias entre adolescentes, verificando os fatores de risco relacionados. Os resultados apontam que o uso de substâncias psicoativas pode se tornar um comportamento relativamente comum nessa fase - especialmente entre grupos vulneráveis e expostos a fatores de risco, como a disponibilidade de drogas, ambiente comunitário sem acesso à cultura e esporte, evasão escolar, problemas familiares, entre outros.

Após a puberdade, o indivíduo muda aos poucos a sua maneira de ser, e muitas vezes essa mudança faz com que o adolescente busque um meio ao qual se identifique. Amigos e colegas por exemplo, podem ser fortes influências para a maioria dos jovens que fazem uso do álcool, motivados pela busca de diversão, prazer, quebra de rotina e redução da ansiedade e estresse (10).

Segundo o artigo L (18), que teve como objetivo revisar os modelos de prevenção do uso indevido de substâncias psicoativas em ambiente escolar, a ampliação do campo de intervenções, que inclui a escola, a comunidade, o desenvolvimento social e atenção à saúde, implica no fim da prevenção restrita para adentrar no conceito de promoção de saúde.

A família, a escola, os grupos e a comunidade onde o jovem vive possuem um papel importante como fatores de proteção, ainda que desenvolvam-se como fatores de risco se exercerem influências que levem ao consumo de substâncias psicoativas. Portanto, percebese a necessidade da construção de espaços de interação comunitária para que se fortaleça ainda mais a discussão em vários aspectos sobre substâncias psicoativas $(14,12)$.

A principal preocupação da promoção da saúde do adolescente é de estimular nos jovens comportamentos e estilos de vida saudáveis que se transformem em motivação para o autocuidado (17). Conforme o artigo L (18), a escola deve ser um espaço de aprendizado e desenvolvimento contínuo, que incentive uma maior participação dos pais em atividades curriculares e extracurriculares, promovendo ações conjuntas, trazendo a comunidade para dentro da escola.

Conforme a pesquisa do artigo A (13), onde os autores realizaram ações educativas em uma escola situada numa área considerada vulnerável devido ao tráfico e uso de substâncias psicoativas, constatou-se que os alunos tinham grande conhecimento em relação a utilização e sobre os efeitos das substâncias psicoativas. Mas, nenhum deles tinha conhecimento sobre seus efeitos fisiológicos, psicológicos e sociais. Assim como, foi possível perceber que as drogas e o seu uso estão diretamente relacionados à violência no cotidiano dos discentes.

Ainda, segundo os autores da pesquisa do artigo A (13), foi possível constatar o aperfeiçoamento do conhecimento, onde os alunos reconheceram a importância das ações no processo de ensino-aprendizagem, bem como o desenvolvimento do senso crítico e capacidade de escolha consciente, favorecendo a diminuição do uso de substâncias 
psicoativas. Desse modo, utilizando o ato de educar para prevenir percebe-se o desenvolvimento da reflexão, da autonomia e da capacidade de escolha consciente pelos adolescentes; onde, tais práticas condizem com estratégia de redução de danos.

Uma reflexão teórica realizada pelo estudo I (17) afirma que não deve-se limitar a ações isoladas, mas enfatizar a orientação e mobilização dos adolescentes, enfocando ações de redução de danos, reabilitação e socialização. É importante que a escola fale sobre as substâncias psicoativas dentro de um contexto amplo, que possibilite a responsabilidade do indivíduo sobre à sua vida e à sua saúde. Portanto, deve-se abordar questões como: poluição, solidão, o padrão de vida competitivo e imediatista, e outros temas que estimulem a reflexão sobre padrões de comportamento adotados pela sociedade em que vivemos. Dessa maneira, o modelo de educação para a saúde parece promissor por ser coerente com o papel da escola: um lugar de formação e inclusão social, e não apenas um espaço de transmissão de informações (18).

O controle social e institucional do uso de substâncias psicoativas é discutido pela análise histórica de diversos modelos praticados, inclusive estuda-se sobre as mudanças no quadro político brasileiro e dos novos valores da sociedade, destacando-se assim a estratégia de redução de danos (29).

\subsection{Redução de danos}

Na história das políticas de prevenção de drogas é possível identificar duas perspectivas: da correção/guerra às drogas e da coesão/redução de danos. A primeira tem caráter proibicionista, acredita em uma sociedade sem drogas (13), e em um tratamento com ênfase na abstinência (7). A segunda fundamenta-se na estratégia de redução de danos, que parte de uma visão humanista e socioeducativa, fundada no fortalecimento afetivo e no desenvolvimento da capacidade de escolha (13).

A experiência da 'guerra às drogas' acumulou muitos fracassos traduzidos em recursos exorbitantes dispendidos com baixa efetividade e uma vasta contabilidade de vidas perdidas, violência, corrupção e ascensão de organizações criminosas. Na perspectiva da correção, se considera que os males da sociedade (pobreza, violência e desordem) tem a sua origem no uso de drogas (30).

O estudo D (19) esclarece que no paradigma da coerção, a solução para tais males seria criminalizar traficantes e usuários para reprimir a oferta do produto (droga). Na teoria, ocorreria falta no mercado e as pessoas usariam menos drogas, mas na realidade acontece o oposto. Esse pensamento resulta da utopia de que é possível eliminar o consumo de drogas da sociedade.

A lógica da abstinência deriva da psicologia clássica e é adotada por muitas instituições privadas e filantrópicas. Porém, percebe-se que o isolamento cria um ambiente descontextualizado e artificial, facilitando a recaída (24).

O consenso em torno da coerção e do proibicionismo fracassou e já é possível constatar mudanças no cenário regulatório. Países como Uruguai e Canadá adotaram novas abordagens em suas políticas de drogas, seguidos de perto por Estados Unidos, México, Colômbia, Portugal e Espanha. No lugar da proibição e da repressão, urge adotar um desenho regulatório para as drogas ilegais semelhante ao que existe em relação ao tabaco, às bebidas alcoólicas e aos fármacos. Nesse sentido, deixar de criminalizar a produção, a comercialização e a posse para uso pessoal é pressuposto necessário e indispensável, pois o aumento da repressão às drogas alimenta um ciclo vicioso, servindo de incentivo para que traficantes armem-se mais e ajam com mais violência para manter o controle do mercado ilícito. Portanto, descriminalizar e assumir a dependência como problema de saúde pública pode favorecer a redução do uso de drogas, do tráfico, da violência e da 
população carcerária (31).

Diante da compreensão de que este fenômeno não pode ser eliminado, a visão da coerção passou a ser duramente criticada e reorientada a partir de uma perspectiva social e humanista, que percebe a ligação do abuso de drogas com a falta de moradia, educação e saúde $(2,14,23,24,30,31)$.

A revisão de literatura realizada pelo estudo D (19) aponta que a estratégia de redução de danos é diferente de outras formas de cuidado que exigem que a pessoa seja abstinente como prioridade para o início do tratamento. De acordo com a ótica de redução de danos, o ideal de abstinência não é um requisito aceitável para todos, pois priva muitos cuidados.

Conforme enfatiza o artigo L (18) a proposta da redução de danos visa amenizar a dualidade entre uso ou abstinência do centro das discussões, para poder desenvolver ações de promoção de saúde com toda a população escolar, sem qualquer discriminação. Assim, os conceitos e ações de promoção de saúde podem ser trabalhados de forma integral e sem o risco de cair em juízo de valor. Cada aluno, ao longo do seu desenvolvimento, passaria a ser livre e apto para elaborar a sua própria equação de vida saudável.

As estratégias de redução de danos recorrem para as questões éticas e humanizadas, como a promoção da saúde e os direitos humanos. A promoção da saúde oferece o protagonismo como um contraponto à medicalização da assistência, visando a autonomia. Assim, deve-se constituir meios para identificar necessidades e mudar favoravelmente as condições de vida, saúde e trabalho. Tal concepção é coerente com a Política Nacional de Promoção da Saúde de 2018 (20) que tem como objetivo promover a equidade e a melhoria das condições de vida, ampliando a potencialidade da saúde individual e coletiva e reduzindo vulnerabilidades e riscos à saúde.

Em abril de 2019, a Política Nacional sobre Drogas foi reformulada, excluindo a proposta da redução de danos e enfatizando o tratamento baseado na abstinência, debate contrário à tendência internacional de abordagem da resolução dos problemas sobre as substâncias psicoativas $(21,22)$.

Várias evidências confirmam a ineficiência dos programas de abstinência, tendo em vista que, na maioria dos casos, o usuário acaba retornando ao consumo (23). Entende-se esta estratégia como uma forma radical de tentar acabar com o consumo das substâncias. Como alternativa às medidas repressivas que retiram os usuários do convívio social, a redução de danos, por exemplo, pode produzir uma intervenção direta na estrutura de vida dos usuários sem retirar suas liberdades individuais (24).

$\mathrm{O}$ artigo $\mathrm{M}$ (25) analisa a experiência de um abrigo situado na cidade de Campinas SP, que atende crianças e adolescentes em situação de rua, e que também fazem uso de substâncias psicoativas. Os resultados, evidenciam que a proposta da abstinência como forma de tratamento configurou-se por algum tempo como única escolha para indivíduos que decidiam mudar a conduta sobre o uso abusivo das substâncias psicoativas. É uma forma de tratamento muito utilizada, principalmente nos modelos de comunidades terapêuticas, produzindo resultados positivos para alguns, mas causando desistência por falta de adaptação. O estudo conclui que a abstinência, por si só, não constitui alternativa adequada para a maioria dos que se inserem nesta população alvo.

Utilizar a estratégia de redução de danos com adolescentes deve ir em direção à intervenção precoce. Para a proposta, necessita-se de articulação entre os segmentos que transpassem a vida da população mais vulnerável: educação, família, assistência social, saúde e justiça. A redução de danos efetivamente se dará no momento em que houver uma reforma na estrutura dos meios de acesso e no desenvolvimento do território ao qual essa população está inserida (8).

É importante salientar que, possivelmente, muitos jovens irão experimentar algum tipo de substância para buscarem sensações de plenitude. Por isso, é essencial que ele possam 
fazer isso após uma avaliação dos riscos envolvidos, ou seja, estando conscientes das possíveis consequências. Autores relatam que se a experiência e o registro dos limites encontrarem-se bem organizados, é provável que o indivíduo consiga cuidar de si sem rupturas (26). Assim, com a estratégia de redução de danos se permite maior respeito à autonomia e à dignidade de cada um, o que se afasta do modelo repressor baseado no paradigma proibicionista vigente.

É necessário atuar no desenvolvimento de instrumentos mais adequados para a interpretação da realidade pessoal e de guias para a intervenção individual, coletiva e social (25). Para alguns, pode parecer inadequado propor estratégias de redução de danos como uma forma de tratamento no caso de adolescentes, porque é um grupo vulnerável, ainda imaturo, que deve ser protegido contra danos. Porém, alguns jovens têm grande necessidade de cuidados de saúde, e estratégias de redução de danos podem criar vínculos como condição para receber cuidados (19).

O papel do educador, seja na escola, na família ou na unidade de saúde, é possibilitar a abertura e tratar das problemáticas atuais que motivam o uso das substâncias psicoativas. Deve-se tratar com igualdade, tanto os jovens que nunca fizeram uso, quanto os que certamente já experimentaram ou que fazem uso esporádico delas, questionando as alternativas possíveis a esse uso. O papel do enfermeiro nesse sentido é de extrema relevância, pois aproxima o jovem ao serviço de saúde.

\subsection{O papel do enfermeiro}

De acordo com o artigo K (28), por ter se transformado em um problema de saúde pública, o uso de substâncias psicoativas na adolescência exige um cuidado especializado, ao ter que encarar as diferentes questões e transformações do adolescente, considerando o olhar sobre si e sobre o mundo.

O artigo E (10) afirma que é importante quebrar as barreiras que dividem o profissional de saúde e o adolescente. É necessário ir até ele, conhecer a sua realidade e seus projetos futuros, identificar problemas que interfiram na qualidade de vida. Uma estratégia já existente dessa aproximação com o enfermeiro e o adolescente dá-se pelo Programa Saúde na Escola (PSE) que foi criado em 2007 pelo Decreto Presidencial no 6.286 (27). A base do programa é a articulação entre estabelecimentos de ensino e rede básica de saúde, e seu objetivo é contribuir para a formação integral dos estudantes por meio de ações de promoção, prevenção e atenção à saúde, visando o enfrentamento das vulnerabilidades que interferem no desenvolvimento de crianças e jovens.

Em virtude dessa realidade, destaca-se o papel do enfermeiro no desenvolvimento de ações direcionadas ao público jovem. A atenção do enfermeiro não deve ser restrita a programas ministeriais, que têm como objetivo atender de forma pontual, sem levar em consideração o desenvolvimento integral do adolescente (9).

O enfermeiro deve abordar o adolescente que faz uso das substâncias psicoativas de um modo integral e ético, entendendo-o como pessoa integrada em uma sociedade, família e de uma forma educativa. Tal abordagem, que considera a subjetividade desse jovem em uma condição de fragilidade pessoal e moral, causada pelo uso da substância psicoativa, deve envolver a família, a escolas, as instituições com propostas reabilitadoras e a comunidade (9).

E, mais ainda, como educador, o enfermeiro deve priorizar a promoção da saúde do adolescente em uma perspectiva emancipatória que ressalta a sua corresponsabilidade e participação em relação ao uso de substâncias psicoativas. Para exercer esse papel importante, é preciso articular a intersetorialidade e a transdisciplinaridade (9).

Complementando, o artigo I (17) descreve que o enfermeiro deve atuar, de maneira 
interdisciplinar, com outras profissões da área da saúde, praticando a transdisciplinaridade e a intersetorialidade, sensibilizando os jovens num entendimento biopsicossocial, informando sobre substâncias psicoativas e seus problemas relacionados ao uso, buscando obter resultados satisfatórios. A pesquisa aponta a Educação em Saúde se dá como ferramenta de ação do enfermeiro para fazer com que a informação chegue ao adolescente, conscientizando-o sobre a importância de um estilo de vida saudável.

O consumo de substâncias psicoativas por adolescentes deve ser compreendido em sua totalidade, considerando aspectos sociais, econômicos, culturais, familiares e éticos. A responsabilidade por esses jovens não pode ser atribuída apenas ao Estado ou à família. Atualmente, o uso e abuso das substâncias psicoativas entre os adolescentes é um sério problema de saúde pública (9).

No estudo do artigo K (28), foi realizada uma pesquisa exploratória de campo no período de 2005 a 2006, com 30 enfermeiros em cinco municípios da região Centro-Sul Fluminense no Rio de Janeiro. Os resultados mostram que as propostas de trabalho de alguns enfermeiros não enfatizam o modelo de promoção da saúde. Poucos enfermeiros prestavam orientações aos usuários de substâncias psicoativas durante a consulta de enfermagem, abordavam e realizavam busca ativa na comunidade, prestavam esclarecimentos com a finalidade de redução de danos decorrentes do uso abusivo, orientavam e direcionavam o usuário para o tratamento.

Conforme o artigo K (28), a experiência com a atenção a quem faz uso de substâncias psicoativas é repleta de desafios:

Em primeiro lugar, trabalhar numa perspectiva diferente daquela aprendida na formação acadêmica, altamente prescritiva e centrada na doença. Em segundo lugar, enfrentar a sua própria ansiedade, insegurança, preconceito e até incapacidade para lidar com o usuário de álcool e drogas. Em terceiro lugar, programar atividades com base em políticas ministeriais que ainda não estão consolidadas na região e nem valorizadas pelos gestores locais. Em quarto lugar, criar protocolos de atendimento que permitam o monitoramento e avaliação de ações de enfermagem desenvolvidas junto ao usuário de álcool e drogas na região. Em quinto lugar, trabalhar em equipe e em rede, de forma a assegurar a integralidade da assistência (28).

Diante de tantos obstáculos causados pelo uso das substâncias psicoativas, entende-se necessário haver intervenções que possibilitem incluir e entender a singularidade de cada indivíduo, seus motivos e suas angústias. É fundamental que os profissionais tenham um olhar humanizado diante de cada situação, para possibilitar avanços e melhoria na forma de abordagem, podendo ser o início de intervenções que sejam realmente resolutivas, através do acolhimento, da escuta, do plano terapêutico individualizado e de programas sociais.

\section{Considerações finais}

As substâncias psicoativas estão presentes desde o início da história da humanidade, destacando-se por proporcionar satisfação do corpo e da mente, principalmente diante dos diversos problemas que as pessoas enfrentam no decorrer de suas vidas. As substâncias não existem somente entre as classes marginalizadas, é um produto consumido por qualquer pessoa e de qualquer classe.

O consumo de substâncias psicoativas por adolescentes deve ser compreendido em sua totalidade, considerando aspectos sociais, econômicos, culturais e éticos. Evidenciou-se que a responsabilidade pelos jovens não deve ser atribuída apenas ao Estado ou à família, mas sim a toda a comunidade que o cerca, como a escola e profissionais de saúde. 
Se torna necessário fortalecer as lutas não repressivas que prezam pela humanização de quem faz uso das substâncias psicoativas, que muitas vezes são submetidos ao controle das políticas de segurança pública, que geralmente preocupam-se em somente reproduzir o estado atual que garante cada vez mais lucros à indústria do combate as drogas, bem como a manutenção da segregação social/racial. A carência de políticas realistas é preocupante, “... se torna importante estabelecer a necessidade de buscar nos dados sobre as realidades de consumo e suas especificidades socioculturais, os subsídios para a elaboração de políticas e leis realmente eficazes..." (29), necessita-se de programas e práticas humanizadas que possibilite a individualidade de cada um e não enfatize somente a substância como foco principal.

\section{Referências}

1. Santos VB, Miranda M. Projetos/programas de redução de danos no Brasil: uma revisão de literatura. Revista Psicologia, Diversidade e Saúde 2016; 5(1): 106-118.

2. Soares CB. Adolescentes, Drogas e Aids (Avaliando a Prevenção e Levantando Necessidades). Tese (Doutor em Educação), São Paulo, USP (Universidade Federal de São Paulo), 1997.

3. Tissot ZL, Hildebrandt LM, Leite MT, Martins RV, Consentino SF. Álcool e outras drogas e a implantação da política de redução de danos no brasil: revisão narrativa. Revista de Atenção à Saúde 2015; 13(43): 79-89.

4. Leopardi MT. Teorias em Enfermagem - Instrumentos para a prática. Florianópolis, NFR/UFSC; Ed. Papa-Livros, 1999.

5. Mendes KDS, Silveira RCCP, Galvão CM. Revisão Integrativa: método de pesquisa para a incorporação de evidências na saúde e na enfermagem. Texto \& Contexto Enfermagem 2008; 17(4): 758-64.

6. MINAYO MCS. Pesquisa social: teoria, método e criatividade. 30. ed. Petrópolis. Vozes, 2011.

7. Silva AG, Rodrigues TCL, Gomes KV. Adolescência, vulnerabilidade e uso abusivo de drogas: a redução de danos como estratégia de prevenção. Revista de Psicologia Política 2015; 15(33): 335-354.

8. Araújo ATS, Silva JC, Oliveira FM. Infância e adolescência e redução de danos/intervenção precoce: Diretrizes para intervenção. Revista Psicologia Argumento 2013; 31(72): 145-154.

9. Valença CN, Brandão ICA, Germano RM, Vilar RLA, Monteiro AI. Abordagem da dependência de substâncias psicoativas na adolescência: reflexão ética para a Enfermagem. Escola Anna Nery Revista de Enfermagem 2013; 17(3): 562-567.

10. Rozin L, Zagonel IPS. Adolescentes que fazem uso nocivo/abusivo de álcool: percepção de risco e proteção para dependência. Revista Eletrônica de Enfermagem 2013; 15(3): 687-95.

11. Feffermann M, Figueiredo R. Redução de Danos como Estratégia de Prevenção de Drogas entre Jovens. Boletim do Instituto de Saúde 2006; (40): 37- 40.

12. Conceição MIG, Oliveira MCS. A relação adolescente-drogas e as perspectivas da nova legislação sobre drogas. Revista de Informação Legislativa 2008; 45 (180): 253-262.

13. Junior WAR, Souza RG, Cruz ERB, Leite AG, Almeida LM. Prevenção ao uso de drogas no ambiente escolar através do processo de sensibilização e conscientização. Carpe Diem: Revista Cultural e Científica do UNIFACEX 2016; 14 (1): 31-42.

14. Castro MS, Rosa LCS. Prevenção do uso de drogas: adolescência, família e escola. Artigo. Teresina. Universidade Federal do Piauí - UFPI, 2013.

15. Faustino NA. O consumo de bebidas alcóolicas por adolescentes do ensino fundamental. Artigo. Curitiba. Universidade Federal do Paraná, 2015.

16. Raupp L, Milnitsky-sapiro C. Adolescência, drogadição e políticas públicas: recortes no contemporâneo. Revista Estudos de Psicologia 2009; 26 (4): 445-454.

17. Cavalcante MBPT, Alves MDS, Barroso MGT. Adolescência, álcool e drogas: uma revisão na perspectiva da promoção da saúde. Escola Anna Nery Revista de Enfermagem 2008; 12: 555-59.

18. Moreira FG, Silveira DX, Andreolli SB. Redução de danos do uso indevido de drogas no contexto da 
escola promotora de saúde. Ciência \& Saúde Coletiva 2006; 11 (3): 807-816.

19. Passos IF, Lima ICBF. Política de drogas: que impacto isso tem nas crianças e nos jovens? Revista Psicologia e Sociedade 2013; 25.

20. BRASIL. Ministério da Saúde. Secretaria de Vigilância em Saúde. Secretaria de Atenção à Saúde. Política Nacional de Promoção da Saúde: PNPS: Anexo I da Portaria de Consolidação no 2, de 28 de setembro de 2017, que consolida as normas sobre as políticas nacionais de saúde do SUS/ Ministério da Saúde, Secretaria de Vigilância em Saúde, Secretaria de Atenção à Saúde. - Brasília, 2018 [acesso em 21 mai 2019]. Disponível em: http://bvsms.saude.gov.br/bvs/publicacoes/politica_nacional_promocao_saude.pdf

21. BRASIL. Ministério da Saúde. Portaria $n^{\circ} 1.028$, de $1^{\circ}$ de julho de 2005. Determina que as ações que visam à redução de danos sociais e à saúde, decorrentes do uso de produtos, substâncias ou drogas que causem dependência, sejam reguladas por esta Portaria, 2005 [acesso em 10 abr 2019]. Disponível em: http://bvsms.saude.gov.br/bvs/saudelegis/gm/2005/prt1028_01_07_2005.html

22. Inglez-dias A, Ribeiro JM, Bastos FI, Page K. Política de Redução de Danos no Brasil. Ciência \& Saúde Coletiva 2014; 19 (1): 147-158.

23. Alves YDD. Jamais fomos zumbis: contexto social e craqueiros na cidade de São Paulo. Artigo. Universidade Federal da Bahia - Programa de Pós-Graduação em Antropologia, 2015.

24. Araújo FS. Quebrando estigmas: uma alternativa ao proibicionismo das drogas por meio da redução de danos. Cadernos de Saúde Pública, 2019; 35 (3): e00014019.

25. Malfitano APS, Lopes RE. Apontamentos de campo acerca de uma experiência de educação não-formal com crianças e adolescentes em situação de rua. Periódico do Programa de Pós-Graduação em Educação da UCDB, 2004.

26. Niel M, Silveira DX. Drogas e Redução de Danos: uma cartilha para profissionais de saúde. Ministério da Saúde, São Paulo, 2008.

27. Brasil. Ministério da Saúde. Decreto ${ }^{\circ}$ 6.286, de 5 de dezembro de 2007, que institui o Programa Saúde na Escola (PSE), e dá outras providências, 2007 [acesso em 21 mai 2019]. Disponível em: http://www.planalto.gov.br/ccivil_03/_Ato2007-2010/2007/Decreto/D6286.htm

28. Gonçalves SSPM, Tavares CMM. Atuação do enfermeiro na atenção ao usuário de álcool e outras drogas nos serviços extra-hospitalares. Escola Anna Nery Revista de Enfermagem 2007; 11(4): 98-586.

29. Filho AN, Macrae E, Tavares LA, Rêgo M. Toxicomanias: incidências clínicas e socioantropológicas. Salvador 2009 [acesso em 08 jan 2020]. Disponível em: http://books.scielo.org/id/qk/pdf/nery9788523208820.pdf

30. Assis JT, Barreiros CA, Jacinto ABM, Kinoshita RT, Macdowell PL, Mota TD, Nicácio F, Schorn MC, Souza IS, Trino AT. Política de saúde mental no novo contexto do Sistema Único de Saúde: regiões e redes. Divulgação em Saúde para Debate 2014; 52: 88-113.

31. Brasil. Ministério da Saúde. Boletim de Análise Político-Institucional / Instituto de Pesquisa Econômica Aplicada - Política de Drogas. Brasília 2018 [acesso em 13 mar 2020]. Disponível em: https://www.ipea.gov.br/portal/images/stories/PDFs/boletim_analise_politico/181206_bapi_18.pdf 